\title{
Kinetics of batch microbial degradation of phenols by indigenous Pseudomonas fluorescence
}

\author{
${ }^{1 *}$ S. E. Agarry; ${ }^{2}$ B. O. Solomon \\ ${ }^{1}$ Biochemical Engineering Research Unit, Department of Chemical Engineering, Ladoke Akintola University of \\ Technology, Ogbomoso, Nigeria \\ ${ }^{2}$ Biochemical Engineering Research Unit, Department of Chemical Engineering, Obafemi Awolowo University, \\ Ile-ife, Nigeria
}

Received 9 November 2007; revised 28 December 2007; accepted 19 January 2008; available online 10 March 2008

\begin{abstract}
The potential of various organisms to metabolize organic compounds has been observed to be a potentially effective means in disposing of hazardous and toxic wastes. Phenols and their compounds have long been recognized as one of the most recalcitrant and persistent organic chemicals in the environment. The bioremediation potential of an indigenous Pseudomonas fluorescence was studied in batch culture using synthetic phenol in water in the concentration range of $(100-500) \mathrm{mg} / \mathrm{L}$ as a model limiting substrate. The effect of initial phenol concentration on the degradation process was investigated. Phenol was completely degraded at different cultivation times for the different initial phenol concentrations. Increasing the initial phenol concentration from $100 \mathrm{mg} / \mathrm{L}$ to $500 \mathrm{mg} / \mathrm{L}$ increased the lag phase from 0 to $66 \mathrm{~h}$ and correspondingly prolonged the degradation process from $84 \mathrm{~h}$ to $354 \mathrm{~h}$. There was decrease in biodegradation rate as initial phenol concentration increased. Fitting data into Monod kinetic model showed the inhibition effect of phenol The kinetic parameters have been estimated up to initial phenol concentration of $500 \mathrm{mg} /$ L. The $r_{\text {smax }}$ decreased and $K_{s}$ increased with higher concentration of phenol. The $r_{\text {smax }}$ has been found to be a strong function of initial phenol concentration. The culture followed substrate inhibition kinetics and the specific phenol consumption rates were fitted to Haldane, Yano and Koga, Aiba et al., Teissier and Webb models. Between the five inhibition models, the Haldane model was found to give the best fit. Therefore, the biokinetic constants estimated using these models showed good potential of the Pseudomonas fluorescence and the possibility of using it in bioremediation of phenol waste effluents.
\end{abstract}

Key words: Biodegradation, kinetic model, batch cultivation, bioreactor, concentration

\section{INTRODUCTION}

Phenol and its derivatives is the basic structural unit in a wide variety of synthetic organic compounds (Annadurai et al., 2000). It is an organic, aromatic compound that occurs naturally in the environment (Prpich and Daugulis, 2005), but is more commonly produced artificially from industrial activities such as petroleum processing, plastic manufacturing, resin production, pesticide production, steel manufacturing and the production of paints and varnish (Mahadevaswamy et al., 1997; Bandyopadhyay et al., 1998). This aromatic compound is water-soluble and highly mobile (Collins and Daugulis, 1997) and as such waste waters generated from these industrial activities contain high concentrations of phenolic compounds (Chang et al., 1998) which eventually may reach down

*Corresponding Author Email: sam_agarry@yahoo.com Tel./Fax: +23 48055529705 to streams, rivers, lakes, and soil, which represent a serious ecological problem due to their widespread use and occurrence throughout the environment (Fava et al., 1995). Phenol is a listed priority pollutant by the U.S. Environmental Protection Agency (EPA, 1979) and is considered to be a toxic compound by the Agency for Toxic substances and Disease Registry (ATSDR, 2003). The adverse effects of phenol on health are well documented (Calabrese and Kenyon, 1991) and death among adults has been reported with ingestion of phenol ranging from 1 to $32 \mathrm{~g}$ (Prpich and Daugulis, 2005). The low volatility of phenol and its affinity for water make oral consumption of contaminated water the greatest risk to humans (Prpich and Daugulis, 2005). A variety of techniques involving physical, chemical and biological methods have been used for the removal of phenol from industrial effluents and contaminated 
waters with bioremediation receiving the most attention due to its environmental friendliness, its, ability to completely mineralize toxic organic compounds and of low-cost (Kobayashi and Rittman, 1982; Prpich and Daugulis, 2005). Microbial degradation of phenol with different initial concentrations ranging from 50-2000 $\mathrm{mg} / \mathrm{L}$ have been actively studied using shake flask, fluidized-bed reactor, continuous stirred tank bioreactor, multistage bubble column reactor, air-lift fermenter and two phase partitioning bioreactor methods (Bettmann and Rehm, 1984; Sokol, 1988; Annadurai et al., 2000; Reardon et al., 2000; Ruiz-ordaz et al., 2001; Oboirien et al., 2005; Prpich and Daugulis, 2005; Saravanan et al., 2008) and these studies have shown that phenol can be aerobically degraded by wide variety of fungi and bacteria cultures such as Candida tropicalis (Ruiz-ordaz et al., 2001, Chang et al., 1998; Ruiz-ordaz et al., 1998); Acinetobacter calcoaceticus (Paller et al., 1995); Alcaligenes eutrophus (Hughes et al., 1984; Leonard and Lindley, 1998); Pseudomonas putida (Hill and Robinson, 1975; Kotturi et al., 1991; Nikakhtari and Hill, 2006); and Burkholderia cepacia
G4 (Folsom et al.,1990, Solomon et al.,1994). In microbial degradation of phenol under aerobic conditions, the degradation is initiated by oxygenation in which the aromatic ring is initially monohydroxylated by a mono oxygenase phenol hydroxylase at a position ortho to the pre-existing hydroxyl group to form catechol. This is the main intermediate resulting from metabolism of phenol by different microbial strains. Depending on the type of strain, the catechol then undergoes a ring cleavage which can occur either at the ortho position thus initiating the ortho pathway that leads to the formation of succinyl Co-A and acetyl Co-A or at the meta position thus initiating the metapathway that leads to the formation of pyruvate and acetaldehyde. Feist ands Hegeman (1969), Hill and Robinson (1975) and Leonard and Lindley (1998) have described the biodegradation or metabolism of phenol by Pseudomonas putida, Pseudomonas cepacia, and Alcaligenes eutrophus respectively via the meta cleavage pathway; while, Paller et al. (1995) described the biodegradation of phenol by Acinetobacter calcoacetium via the ortho cleavage pathway.

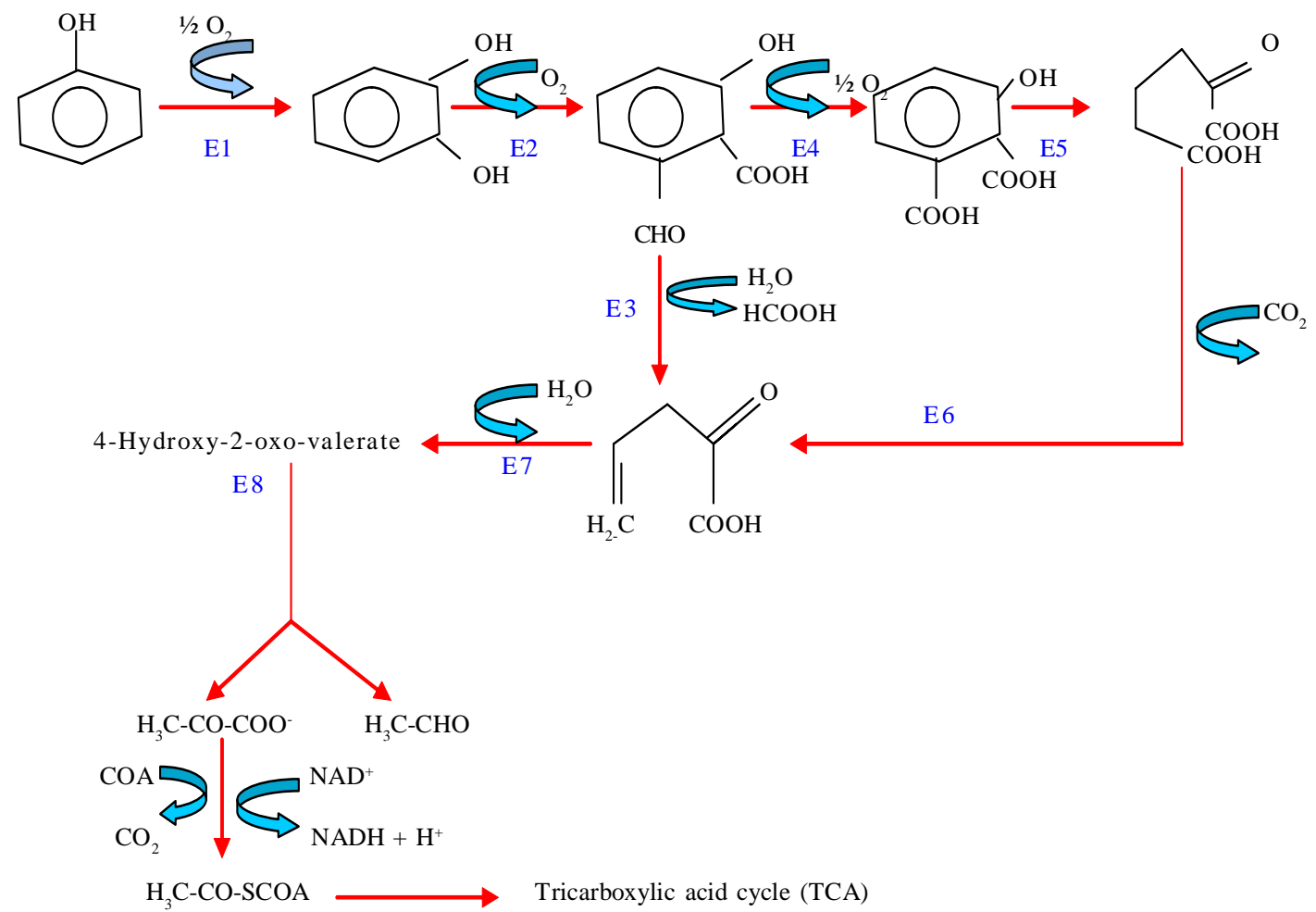

Fig. 1: The meta-cleavage pathway for the biodegradation of phenol

$\mathrm{A}=$ Phenol, $\mathrm{B}=$ Catechol, $\mathrm{C}=2$-Hydroxymuconic semialdehyde, $\mathrm{D}=2$-Hydroxymuconate, $\mathrm{E}=2$ - Oxo- 4- enoadipate, $\mathrm{F}=2$ - $\mathrm{Oxo}$-penta-4-enoate, $\mathrm{G}=$ Pyruvate, H= Acetaldehyde, I= Acetyl Co A, E1= Monooxygenase phenol hydroxylase, E2=Catechol-2, 3- dioxygenase, E3= Hydrolase, E4= Dehydrogenase, E5= Isomerase, E6= Decarboxylase, E7= Hydrotase, E8= Aldolase 
The meta cleavage pathway for the biodegradation of phenol as presented by Feist and Hegeman (1969) is as shown in Fig. 1. A variety of kinetic substrate utilization and inhibition models have been used to describe the dynamics of microbial growth on phenol. Of these various models, the Monod and Andrew (Haldane) equations has been extensively used to describe phenol biodegradation (Bandyopadhyay et al., 1998; Reardon et al., 2000; Oboirien et al., 2005). The Monod (1949) and Haldane (Andrew, 1968) equations are based on the specific growth rate, but may also be related to the specific substrate consumption rate (Edwards, 1970; Solomon et al., 1994). Other kinetic models have been propagated. Sokol (1988) has reported a better fit for a modified Monod-Haldane equation while Schroeder et al. (1997) have shown a better fit for Yano and Koga equation amongst the tested inhibition models. In spite of the rather extensive use of phenol biodegradation processes, surprisingly, little work has been published on phenol microbial degradation kinetics based on specific substrate consumption rate using pure or mixed cultural systems. The objective of this present study was to investigate the degradation potential of an indigenous (local isolates) Pseudomonas fluorescence isolated from an oil-polluted area in Niger-Delta region of Nigeria and the effect of initial phenol (substrate) concentration on its degradation ability.

\section{MATERIALS AND METHODS}

The microorganism Pseudomonas fluorescence being an indigenous strain isolated from an oil-polluted area in Niger-Delta region of Nigeria was procured from the Department of Microbiology, Obafemi Awolowo University, Ile-Ife, Nigeria. The microorganism was maintained on nutrient agar slant and stored at $4{ }^{\circ} \mathrm{C} \pm$ $1^{\circ} \mathrm{C}$ for further use. The mineral salt medium used was modified from the one suggested by Bettman and Rehm (1984). The medium had the following composition per litre : $700 \mathrm{~mL}$ deionized water, $100 \mathrm{~mL}$ buffer solution $\mathrm{A}$, $100 \mathrm{~mL}$ solution $\mathrm{B}, 50 \mathrm{~mL}$ solution $\mathrm{C}$ and $50 \mathrm{~mL}$ solution D. Compositions of each solution were as follows : Buffer solution A composition $\mathrm{K}_{2} \mathrm{HPO}_{4} 1.0 \mathrm{~g}, \mathrm{KH}_{2} \mathrm{PO}_{4}$ $0.5 \mathrm{~g},\left(\mathrm{NH}_{4}\right)_{2} \mathrm{SO}_{4} 0.5 \mathrm{~g}$, deionized water $100 \mathrm{ml}$. Trace element solution $\mathrm{B}$ composition $\mathrm{NaCl} 0.5 \mathrm{~g}, \mathrm{CaCl}_{2} 0.02 \mathrm{~g}$ , $\mathrm{MnSO}_{4} 0.02 \mathrm{~g}, \mathrm{CuSO}_{4} .5 \mathrm{H}_{2} \mathrm{O} 0.02 \mathrm{~g}, \mathrm{H}_{3} \mathrm{BO}_{3} 0.01 \mathrm{~g}$, deionized water $50 \mathrm{ml}$. Solution $\mathrm{C}$ composition $\mathrm{MgSO}_{4} \cdot 7 \mathrm{H}_{2} \mathrm{O} 0.5 \mathrm{~g}$, deionized water $50 \mathrm{~mL}$, Solution D composition $\mathrm{FeSO}_{4}$ 0.02g , Molybdenum powder 0.02g, deionized water $50 \mathrm{~mL}$. To prevent the precipitation of $\mathrm{CaSO}_{4}$ and $\mathrm{MgSO}_{4}$ in storage, the water, buffer solution $\mathrm{A}$; trace elements solution $\mathrm{B}$, solution $\mathrm{C}$ and solution $\mathrm{D}$ were autoclaved at $121^{\circ} \mathrm{C}$ for $15 \mathrm{~min}$. After cooling, all the solutions were then mixed together and kept as stock solution from which known quantities were taken for the cultivation of the microorganisms. A primary culture was prepared by transferring two loops full of microorganisms from an agar slant culture into $100 \mathrm{~mL}$ of feed medium containing $20 \mathrm{~mL}$ of mineral salt medium and $80 \mathrm{~mL}$ of $50 \mathrm{mg}$ phenol solution in a $250 \mathrm{~mL}$ Erlenmeyer conical flask. This was then incubated in a NewBrunwick gyratory shaker (G25-R model, N.J. U.S.A) for $48 \mathrm{~h}$ at a temperature of $30^{\circ} \mathrm{C}$ and agitated with a speed of $120 \mathrm{rpm}$. Thereafter, $10 \mathrm{~mL}$ of the primary culture was transferred into another $100 \mathrm{~mL}$ of feed medium in a $250 \mathrm{~mL}$ Erlenmeyer conical flask and the incubation process was repeated. This was the secondary culture that was used as the inoculums for the degradation studies as this ensures that the organisms had fully adapted to growth on the phenol as sole source of carbon and energy. The experimental studies were carried out in a NewBrunswick Microferm Twin Bioreactor (PH - 22 model, N.J., U.S.A) with 4 litres working volume. $800 \mathrm{~mL}$ of the autoclaved mineral salt medium and $3 \mathrm{~L}$ of phenol solution $(100 \mathrm{mg} / \mathrm{L})$ were measured into the bioreactor vessel and $200 \mathrm{~mL}$ of the inoculums was introduced aseptically to make up 4 litres of working volume. The bioreactor was operated for several hours at a temperature of $30^{\circ} \mathrm{C}$, aeration rate of $3.0 \mathrm{vvm}$ and agitation of $300 \mathrm{rpm}$. Samples were withdrawn at every $6 \mathrm{~h}$ for biomass and phenol analysis. This was done in duplicate and average values were used. The undegraded phenol was estimated quantitatively by measuring its absorbance at $510 \mathrm{~nm}$ wavelength using UV - Visible Spectrophotometer (Lambda 35, Perkin-Elmer, USA) and 4 - amino antipyrene as color indicator (Yang and Humphrey, 1975). The biomass concentration was estimated using the dry weight method. $50 \mathrm{~mL}$ sample of culture broth was withdrawn from the bioreactor and centrifuged (Gallenkamp centrifuge) at $4000 \mathrm{rpm}$ for $20 \mathrm{~min}$ in plastic centrifuge tubes. The supernatant was decanted into small bottles and stored at $4{ }^{\circ} \mathrm{C}$ for subsequent phenol estimation. The pellets was resuspended in de-ionized water and re-centrifuged. The supernatant was decanted and pellets rinsed off from the tube into a pre-weighed $1.2 \mu \mathrm{m}$ pore filter paper (Whatman GF/C). The filter paper saw then dried in 


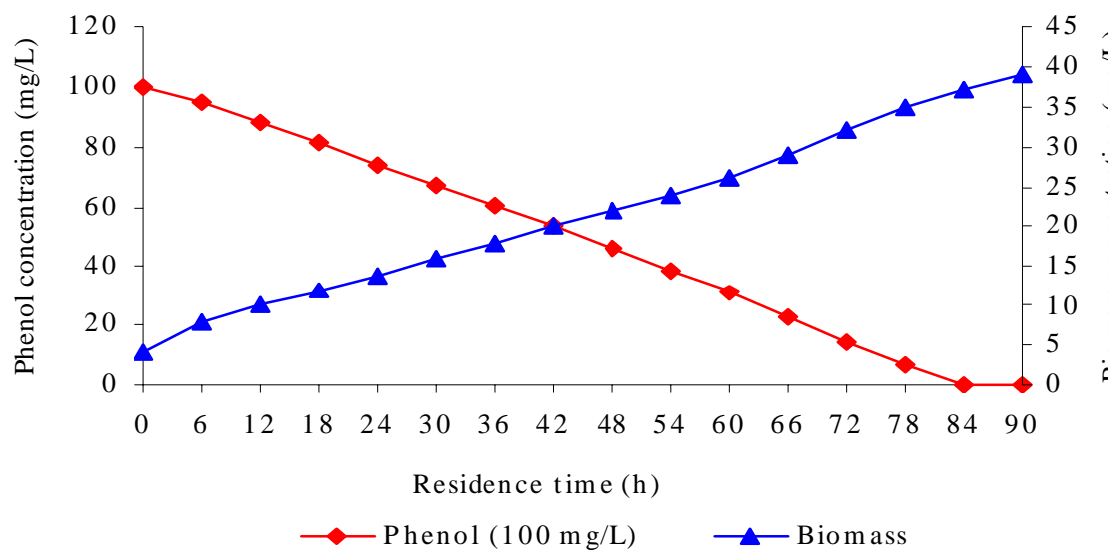

Fig. 2: Experimental data obtained from batch degradation of phenol (100 $\mathrm{mg} / \mathrm{L}$ ) by monoculture of Pseudomonas fluorescence

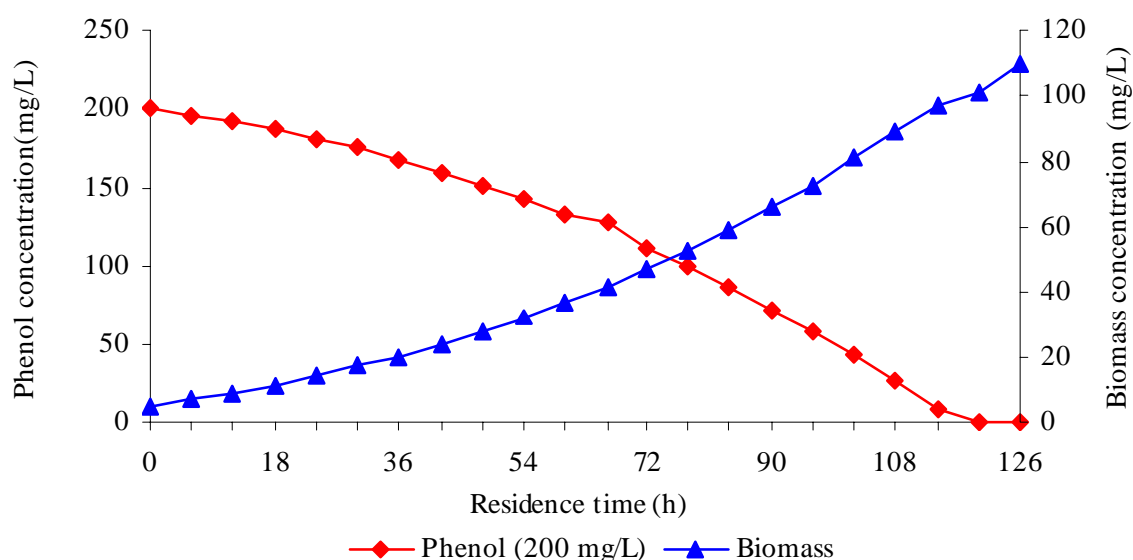

Fig. 3: Experimental data obtained from batch degradation of phenol (200 $\mathrm{mg} / \mathrm{L}$ ) by Pseudomonas fluorescence

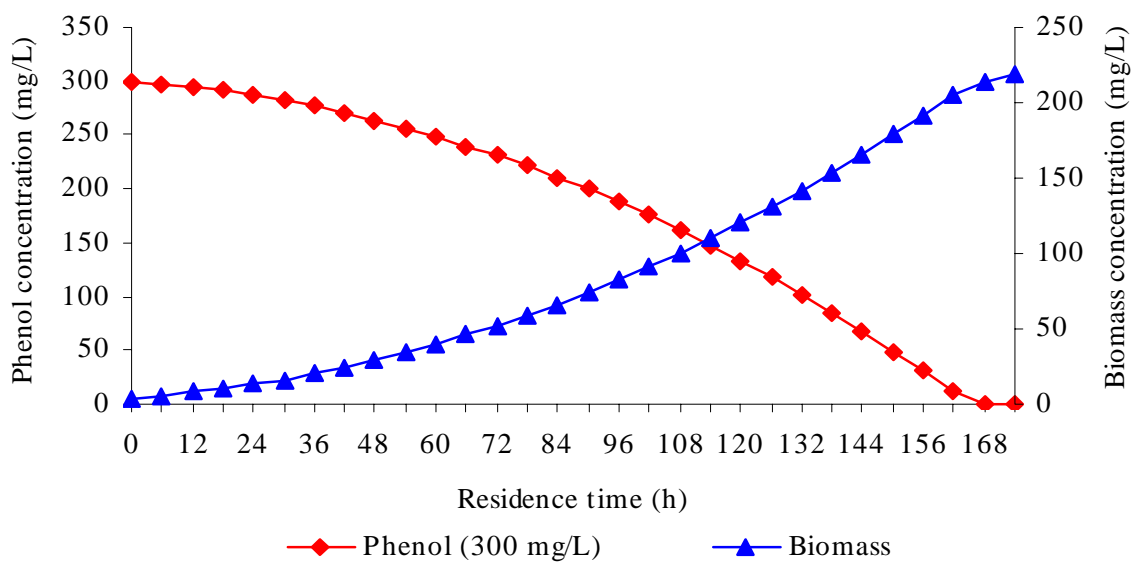

Fig 4: Experimental data obtained from batch degradation of phenol (300 $\mathrm{mg} / \mathrm{L}$ ) by Pseudomonas fluorescence 


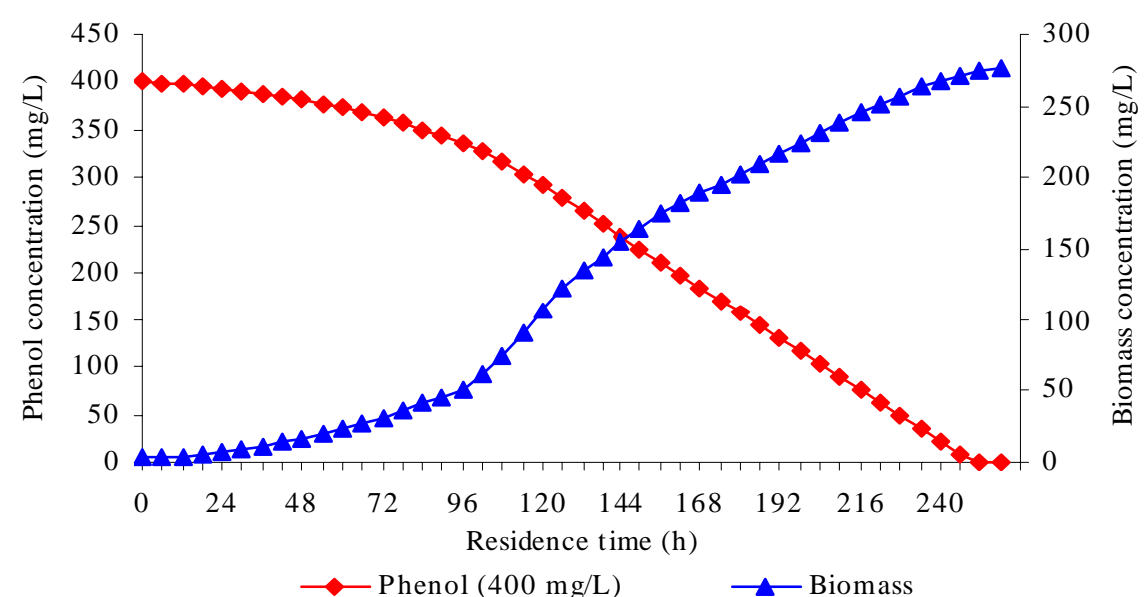

Fig. 5: Experimental data obtained from batch degradation of phenol (400 mg/L) by Pseudomonas fluorescence

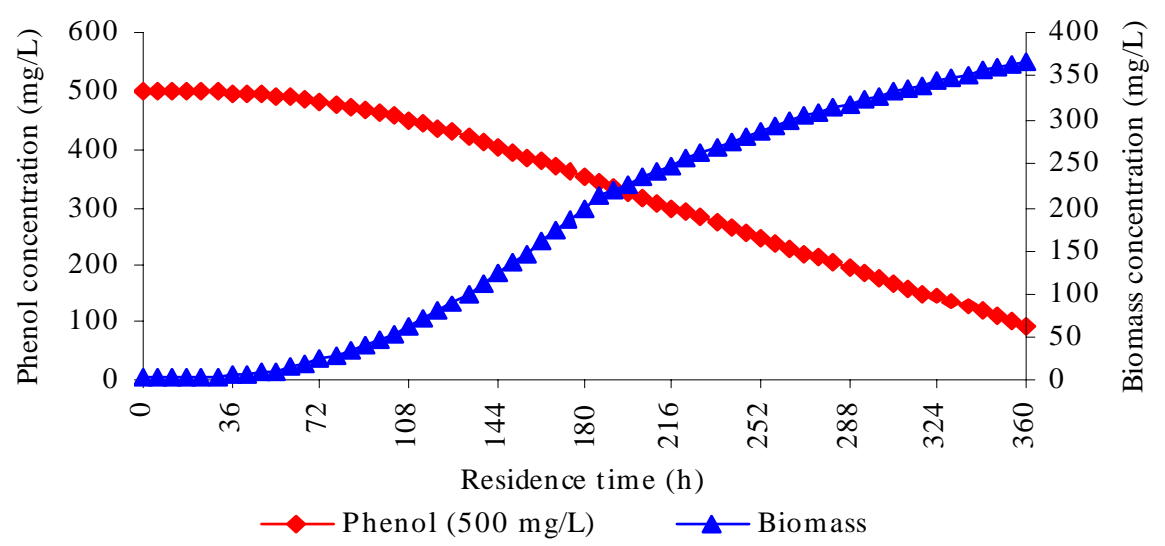

Fig. 6: Experimental data obtained from batch degradation of phenol (500 mg/L) by Pseudomonas fluorescence

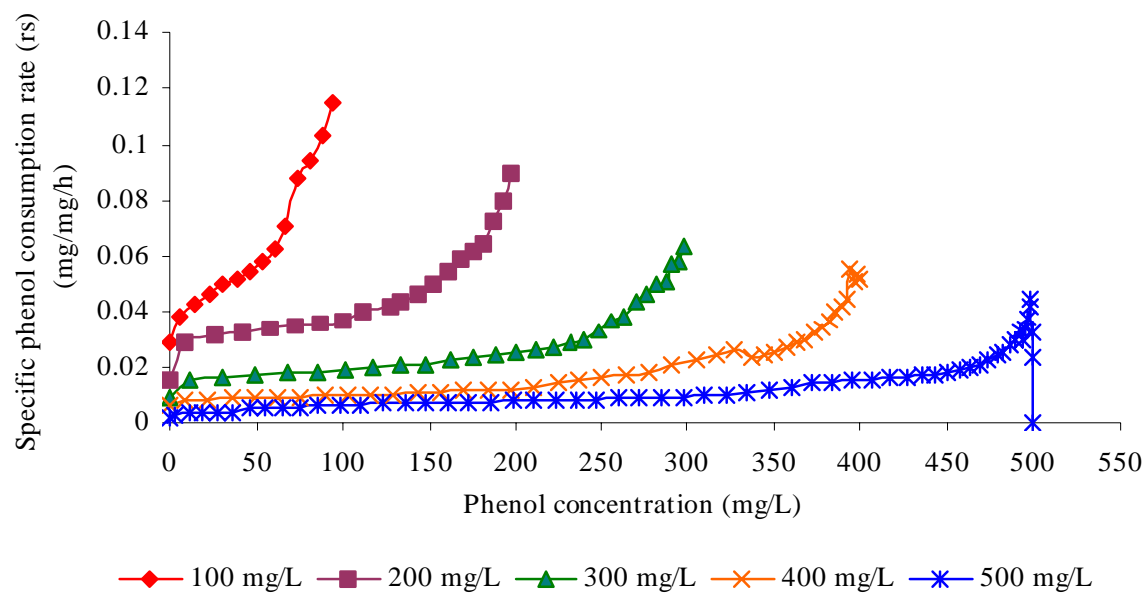

Fig. 7: Specific phenol consumption rate vs phenol concentration for monoculture of Pseudomonas fluorescence 


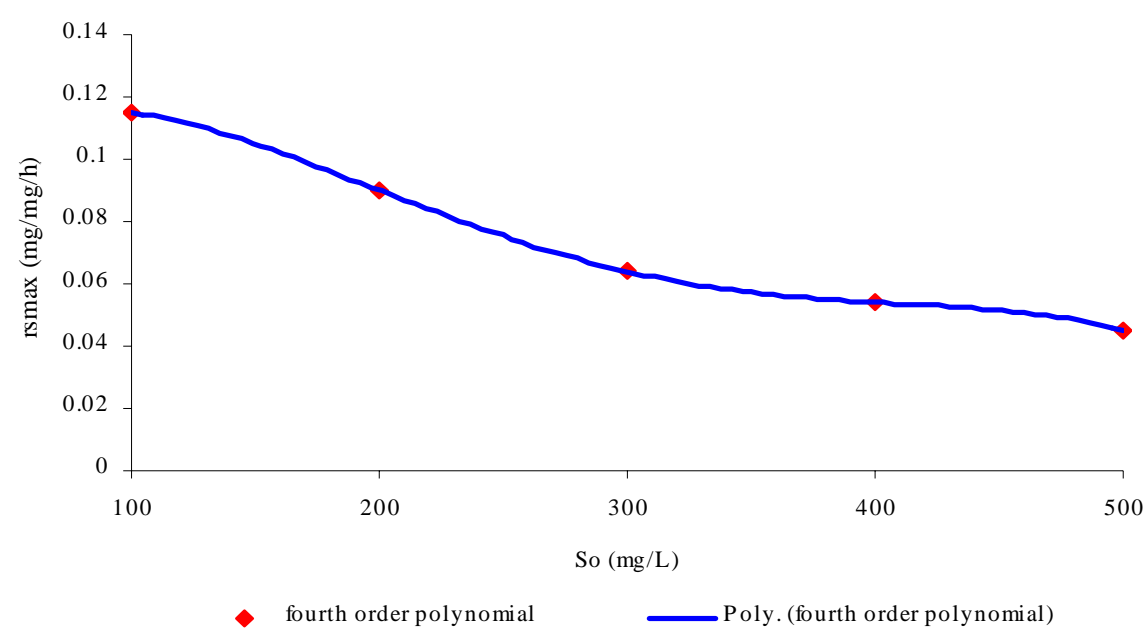

Fig. 8: Variation of rsmax with So for phenol degradation by monoculture of Pseudomonas fluorescence

an oven at $105{ }^{\circ} \mathrm{C}$ for between $12-24 \mathrm{~h}$, cooled in a dessicator at room temperature and re-weighed until a constant dry weight was obtained. The difference between the pre-weighed filter paper and the second weight was used to estimate the dry weight of the biomass.

\section{RESULTS AND DISCUSSION}

Five batch cultivation experiments were carried out using phenol as single limiting substrate for Pseudomonas fluorescence. Different initial phenol concentrations of $100 \mathrm{mg} / \mathrm{L}$ to $500 \mathrm{mg} / \mathrm{L}$ were used. The extent of phenol degradation using these different initial phenol concentrations was investigated for several batch residence times by intermittent sampling. Figs. 2 to 6 shows the biodegradation potential of the indigenous P.fluorescence in degrading synthetic phenol waste in the concentration range of $100 \mathrm{mg} / \mathrm{L}$ to $500 \mathrm{mg} / \mathrm{L}$. Since the degradation proceeds with biomass (cell mass) growth, the Figure also depicts the typical cell growth curve. The cell growth curve has typical exponential and stationary phases with increasing lag phase. It could be seen from Figs. 2 to 6 that the different initial phenol concentrations ranging from $(100$ - 500) mg/L were completely degraded (consumed) at different residence time of $84 \mathrm{~h}, 120 \mathrm{~h}$, $168 \mathrm{~h}, 252 \mathrm{~h}, 354 \mathrm{~h}$, and during these times the biomass correspondingly increased to a maximum of $37 \mathrm{mg} / \mathrm{L}$, $101 \mathrm{mg} / \mathrm{L}, 213 \mathrm{mg} / \mathrm{L}, 274 \mathrm{mg} / \mathrm{L}$, and $362 \mathrm{mg} / \mathrm{L}$ respectively. No lag phase was observed for initial phenol concentration of $100 \mathrm{mg} / \mathrm{L}$ as shown in Fig. 2. However, for initial phenol concentration of $(200,300$,
400, and 500) mg/L corresponding lag phase of 6 h, 18 h, $24 \mathrm{~h}$ and $66 \mathrm{~h}$ was observed respectively as shown in Figs. 3 to 6 . Moreover, it was observed that after the complete degradation or conversion of the different initial phenol concentrations, there was further increase of the biomass at each initial concentration of phenol. This increase may be due to the fact that the added phenol was converted to unknown intermediates that were later consumed. A similar observation has been reported for the isolates of Pseudomonas and Acinetobacter grown on phenol (Hao et al., 2002; Saez and Rittman, 1991; Prpich and Daugulis, 2005). As shown in Figs. 2 to 6, which indicate the comparison of the time course for phenol substrate consumption of all the five batches, it is evident that the rate of degradation decreased with increase in the initial phenol concentration. Bandyopadhyay et al. (1998) and Ruizordaz et al. (2001) reported a similar observation on Pseudomonas putida and Candida tropicalis grown on phenol, respectively. Thus, it is observed that as the initial phenol concentration increased the duration of the lag phase increased; and thereby, prolonging the biodegradation time as a result of decrease in the rate of degradation. This observation is supported by the earlier works of Andrews (1968), Hill and Robinson (1975), Collins and Daugulis (1997), and Oboirien et al. (2005). According to Prpich and Daugulis (2005), the rate of substrate consumption was suggested to be the most important measure of microbe performance. Zilli et al. (1993) gave a similar report. Relatively very few data exists in the literature on this parameter. Most of the data available concerns specific growth rate. It 
Int. J. Environ. Sci. Tech., 5 (2), 223-232, Spring 2008

Table 1: Kinetic constants obtained from the fitting of experimental batch phenol degradation runs data for P.fluorescence to Monod kinetic model

\begin{tabular}{ccc}
\hline $\begin{array}{c}\text { Initial phenol concentration } \\
\mathrm{S}_{\mathrm{o}}(\mathrm{mg} / \mathrm{L})\end{array}$ & $\begin{array}{c}\text { Half-saturation constant } \\
\mathrm{K}_{\mathrm{s}}(\mathrm{mg} / \mathrm{L})\end{array}$ & $\begin{array}{c}\text { Maximum specific phenol consumption } \\
\text { rate } \mathrm{r}_{\mathrm{smax}}(\mathrm{mg} / \mathrm{mg} / \mathrm{h})\end{array}$ \\
\hline 100 & 31.1 & 0.115 \\
200 & 88.7 & 0.09 \\
300 & 176.8 & 0.064 \\
400 & 294.8 & 0.054 \\
500 & 556.4 & 0.045 \\
\hline
\end{tabular}

Table 2: Kinetic parameters value obtained from five kinetic models fitted to the biodegradation data of P.fluorescence

\begin{tabular}{|c|c|c|c|c|c|c|c|}
\hline Model & $\begin{array}{c}\mathrm{r}_{\mathrm{smax}} \\
(\mathrm{mg} / \mathrm{mg} / \mathrm{h})\end{array}$ & $\begin{array}{c}\mathrm{K}_{\mathrm{s}} \\
(\mathrm{mg} / \mathrm{L})\end{array}$ & $\begin{array}{c}\mathrm{K}_{1} \\
(\mathrm{mg} / \mathrm{L})\end{array}$ & $\begin{array}{c}\mathrm{K}_{2} \\
(\mathrm{mg} / \mathrm{L})\end{array}$ & $\begin{array}{c}\mathrm{K}_{\mathrm{i}} \\
(\mathrm{mg} / \mathrm{L})\end{array}$ & $\mathrm{R}^{2}$ & RMSE \\
\hline Yano \& Koga & 38.3 & 105.9 & 0.384 & 31.2 & - & 0.7824 & 0.0300 \\
\hline Teissier & 0.694 & 0.727 & - & - & 0.394 & -3.35 & 0.1001 \\
\hline Aiba et al. & 0.694 & 0.727 & - & - & 0.394 & -2.649 & 0.1001 \\
\hline Webb & 6.283 & -3.369 & -1.493 & - & 54.6 & 0.7837 & 0.0299 \\
\hline Haldane & 0.357 & 50.2 & - & - & 67.7 & 1.000 & 0.0003 \\
\hline
\end{tabular}

was on this basis that the specific phenol (substrate) consumption rate was calculated and plotted against phenol concentration as shown in Fig. 7. As seen from Fig. 7 , the specific phenol consumption rate $\left(r_{s}\right)$ decreased as the phenol concentration (S) decreased for each of the different initial phenol concentrations Therefore, it seems that there is also an influence of the initial phenol concentration on the specific phenol consumption rate. Hinteregger et al. (1992) and Abd-El Hameidshalaby (2003) reported a similar observation According to Layokun et al. (1987) the growth of microorganisms corresponds to the degradation (consumption) of the substrate. Hence, the growth of microorganisms on phenol can be described by the most commonly used kinetic models that can be based on specific substrate consumption rate as proposed by Posten (Solomon et al., 1994) and which have been used by Zilli et al. (1993) and Schroeder et al. (1997). In this work, phenol was completely degraded and kinetic model of Monod (1949) based on specific substrate consumption rate was used to evaluate the degradation of phenol at different initial concentration by the indigenous $P$. fluorescence. The classical method of obtaining kinetic parameters (constants) is to linearize kinetic models. Recently, non-linear least squares computer fitting of data to model equations has been used (Schroeder et al., 1997; Reardon et al.,
2000; Saravanan et al., 2008). The non-linear least square fitting routine of MATLAB 6.5 software package was used to fit the Monod kinetic model to the different batch experimental data. The parameters of Monod $\left(\mathrm{K}_{\mathrm{s}}\right.$ and $r_{\text {smax }}$ ) was fitted to the experimental calculated specific phenol consumption rate and the corresponding phenol concentration under the constraint that $r_{s}$ never exceeds the maximum obtainable specific consumption rate $\left(\mathrm{r}_{\text {smax }}\right)$ and the results are presented in Table 1. As seen from the Table, the Monod parameters $\left(\mathrm{r}_{\text {smax }}\right.$ and $\mathrm{K}_{\mathrm{s}}$ ) show a definite trend of variation. The $\mathrm{r}_{\text {smax }}$ decreased and $\mathrm{K}_{\mathrm{s}}$ increased as the initial phenol concentration increased. Considering the fact that $\mathrm{K}_{\mathrm{s}}$ is inversely related to the affinity of the microbial system for the substrate (Pirt, 1975), this increase of $\mathrm{K}_{\mathrm{s}}$ corresponds to a decrease in affinity of the bacteria ( $P$. fluorescence) for phenol. It is therefore evident that inhibition becomes prominent as initial phenol concentration increased. Thus, the $r_{\text {smax }}$ is a strong function of initial phenol concentration $\left(\mathrm{S}_{0}\right)$ The variation of $r_{\text {smax }}$ with $S_{o}$ has been indicated in Fig.8 and also fitted by the fourth order polynomial fit from which $r_{\text {smax }}$ at any value of $S_{0}$ within the range of 100$500 \mathrm{mg} / \mathrm{L}$ of phenol concentration may be predicted. However, the observation of substrate inhibition due to phenol can be modeled using substrate inhibition models described in literature (Schroeder et al., 1997). 
The experimental results of specific phenol consumption rate variation with initial phenol concentration was fitted to five inhibition models of Haldane (Andrew, 1968), Yano and Koga (1969), Aiba et al. (1968), Teissier (Edwards, 1970), and Webb (Edwards, 1970). The model with the best fit was selected on the basis of highest correlation coefficient $\left(\mathrm{R}^{2}\right)$ and the least root mean square error (RMSE). The kinetic parameters of the models $\left(\mathrm{r}_{\mathrm{smax}}, \mathrm{K}_{\mathrm{s}}\right.$ and $\left.\mathrm{K}_{\mathrm{i}}\right)$ were estimated using the non - linear regression routine of MATLAB 6.5, and the results along with the $\mathrm{R}^{2}$ and RMSE are given in Table 2 . The results revealed that between the five models, Haldane has a correlation coefficient $\left(\mathrm{R}^{2}\right)$ greater than 0.90 and the least root mean square error (RMSE $=0.0003$ ), and thus, indicating a very good fit to the batch experimental data. In this work, the biodegradation potential of phenol by Pseudomonas fluorescence has been examined. It was shown that the organism completely degraded phenol up to a maximum concentration of $500 \mathrm{mg} / \mathrm{L}$ in mineral salt medium, and that, initial phenol concentration has effect on the rate of degradation. The higher the initial phenol concentration, the longer is the lag phase of the culture, and the lower the rate of degradation; thus, the slower the biodegradation becomes. The culture followed substrate inhibition kinetics as indicated by the kinetic parameters value of Monod model equation, in which $\mathrm{r}_{\text {smax }}$ decreased and $\mathrm{K}_{\mathrm{s}}$ increased, as initial phenol concentration increased. Thus, the experimental batch biodegradation data was fitted to Haldane, Yano and Koga, Aiba et al., Teissier, and Webb, substrate inhibition models. It was shown that of all the models, the Haldane model represent the biodegradation data reasonably very well, and hence, may be proposed as the best model to describe the phenol biodegradation behaviour of $P$. fluorescence.

The performance of this indigenous $P$. fluorescence is being compared with well-known effective degraders of phenol with emphasis on maximum specific substrate consumption rate. Reported values of the maximum specific substrate consumption rate $\left(\mathrm{r}_{\text {smax }}\right)$ varied from 0.001 to $2.6 \mathrm{hr}^{-1}$ (Folsom et al., 1990; Zilli et al., 1993; Schroeder et al., 1997). Folsom et al. (1990) and Schroeder et al. (1997) reported an $\mathrm{r}_{\text {smax }}$ value of $2.6 \mathrm{hr}^{-}$ ${ }^{1}$ and $0.4 \mathrm{hr}^{-1}$ for Pseudomonas cepacia G4 respectively. While, Zilli et al. (1993) reported a value of $0.0016 / \mathrm{h}$ for Pseudomonas putida NCIMB 10015. The $\mathrm{r}_{\text {smax }}$ value of $0.357 \mathrm{mg} / \mathrm{mg} / \mathrm{h}$ for $P$. fluorescence was relatively comparable to that of Pseudomonas cepacia G4 ( $\mathrm{r}_{\mathrm{sm}}$
$=0.4 / \mathrm{h}$ ), however greater than that of $P$. putida NCIMB 10015. In conclusion, the biokinetic constants evaluated using the models showed good tolerance and growth of the indigenous organism, and therefore, a complete degradation of the phenol substrate. The performance of the indigenous strain in biodegradation of phenol in the nutrient medium is good.

\section{ACKNOWLEDGMENTS}

The author wishes to thank Professor B. O. Solomon for his useful suggestions, encouragement and supervision of this work. B. O. Solomon wish to express his sincere thanks to the International Foundation for Science (IFS) for the financial support used for the procurement of all the chemicals needed for this work. Nomenclature

$K_{s} \quad$ Half-saturation constant (mg/L)

$K_{i} \quad$ Inhibition constant $(\mathrm{mg} / \mathrm{L})$

$r_{s} \quad$ Specific phenol (substrate) consumption rate (mg/mg/h.)

$r_{\text {smax }}$ Maximum specific phenol (substrate)

consumption rate (mg/mg/h.)

$\mathrm{S}, \mathrm{C}_{\mathrm{s}}$ Substrate (phenol) concentration $(\mathrm{mg} / \mathrm{L})$

Monod (1949): $r_{s}=\frac{r_{s, \max } S}{K_{s}+S}$

Haldane (Andrews, 1968): $\quad r_{s}=\frac{r_{s \max } S}{K_{s}+S+\frac{S^{2}}{K_{i}}}$

Aiba et al. (1968): $r_{s}=r_{s_{\max }} \frac{C_{s_{\exp }}\left(-C_{s} / K_{i}\right)}{K_{s}+C_{s}}$

Teissier (Edwards, 1970):

$r_{s}=r_{s_{\max }}\left[\exp \left(-C_{s} / K_{i}\right)-\exp \left(-C_{s} / K_{s}\right)\right]$

Webb (Edwards, 1970): $r_{s}=r_{s_{\max }} \frac{C_{s}\left(1+C_{s} / K_{i}\right)}{K_{s}+C_{s}+C_{s}^{2} / K_{1}}$

Yano and Koga (1969):

$r_{s}=r_{s_{\max }} \frac{C_{s}}{K_{s}+C_{s}+C_{s}^{2} / K_{1}+C_{s}^{3} / K_{2}^{2}}$ 


\section{REFERENCES}

Abd-El Hameidshalaby, M. El-s. (2003). Biological degradation of substrate mixtures composed of phenol, benzoate and acetate by Burkholderia cepacia G4. Ph.D Thesis. Gesellschaft fur Biotechnologische Forschung mbH, MascheroderWegl, D - 38124 Braunschweig, Germany.

Andrews, J. F. (1968). A mathematical model for the continuous culture of microorganisms utilizing inhibitory substance, Biotechnol. Bioeng., 10, 707-723.

Annadurai, G.; Balan, S. M.; Murugesan, T., (2000). Design of experiments in the biodegradation of phenol using immobilized Pseudomonas pictorium (NICM- 2077) on activated carbon., Bioproc. Eng., 22 (6), $101-107$.

ATSDR, (2003). Agency for toxic substances and disease registry. Medical management guidelines for phenol. Avaiable from: http://www.atsdr.cdc.gov/MHM 1/mmg 115.html.

Bandyopadhyay, K.; Das, D.; Maiti, B. R., (1998). Kinetics of phenol degradation using Pseudomonas putida MTCC 1194., Bioproc. Eng., 18 (5), 373 - 377.

Bettman, H.; Rehm, H. J., (1984). Degradation of phenol by polymer entrapped microorganisms. Appl. Microbiol. Biotechnol., 20 (5), 285 - 290.

Calabrese, E. J.; Kenyon, E. M. (1991). Air toxics and Risk Assessment. Lewis publishers, Chelsea, MI.

Chang, Y. H.; Li, C. T.; Chang, M. C.; Shieh, W. K. (1998). Batch phenol degradation by Candida tropicalis and its fusant, Biotechnol. Bioeng., 60 (3), 391-395.

Collins, L. D.; Daugulis, A. J. (1997). Biodegradation of phenol at high initial concentration in two-phase partitioning batch and fed-batch bioreactors, Biotechnol. Bioeng., 55 (1), 155 162.

Edwards, V. H. (1970). The influence of high substrate concentrations on microbial kinetics, Biotechnol. Bioeng., 12 (5), 679-712.

EPA, (1979). Phenol ambient water quality criteria. Office of planning and standards.Environmental Protection Agency, Washington, D. C. BB296786.

Fava, F.; Armenante, P. M.; Kafkewitz, D.; Marchetti, L., (1995). Influence of organic and inorganic growth supplements on the aerobic biodegradation of chlorobenzoic acid, Appl. Microbiol. Biotechnol., 43 (1), 171-177.

Feist, C.; Hegeman, G. D., (1969). Phenol and benzoate metabolism by Pseudomonas putida: Regulation of tangential pathways, J. Bacteriol., 100 (2), 869-877.

Folsom, B. R.; Chapman, P. J.; Pritchard, P. H. (1990). Phenol and trichloroethylene degradation by Pseudomonas cepacia G4: Kinetics and interactions between substrates., Appl. Environ. Microbiol., 56 (5), 1279 - 1285.

Hao, O.; Kim, M.; Seagren, E.; Kim, H. (2002). Kinetics of phenol and chlorophenol utilization by Acinetobacter isolates., Chemosphere, 46 (6), 797 - 807.

Hill, G. A.; Robinson, C. W. (1975). Substrate inhibition kinetics: phenol degradation by Pseudomonas putida, Biotechnol. Bioeng. 17 (11), 599-615.

Hinteregger, C.; Leitner, R.; Loidl, M.; Fershl, A.; Streichsbier, F. (1992). Degradation of phenol and phenolic compounds by Pseudomonas putida EK 11., Appl. Environ. Microbiol., 37, 252-259.

Hughes, E. J.; Bayly, R. C.; Skurray, R. A. (1984). Evidence for isofunctional enzymes in the degradation of phenol, $\mathrm{m}$ - and $\mathrm{p}$ - toluate, and p-cresol via catechol metacleavage pathways in Alcaligenes eutrophus, J. Bacteriol., 158 (1), 79-83.
Kobayashi, H.; Rittman, B. E. (1982). Microbial removal of hazardous organic compounds. Environ. Sci. Tech., 16 (3), $170-183$.

Kotturi, G.; Robinson, C. W.; Inniss, W. E. (1991). Phenol degradation by a psychrotrophic strain of Pseudomonas putida., Appl. Microbial. Biotechnol., 34 (4), 539 -543.

Layokun, S. K.; Umoh, E. F.; Solomon, B. O. (1987). A kinetic model for the degradation of dodecane by $P$. fluorescens isolated from the oil polluted area, Warri in Nigeria, J. Nsche., 16, 48-52.

Leonard, D.; Lindley, N. D., (1998). Carbon and energy flux constraints in continuous cultures of Alcaligenes eutrophus grown on phenol, Microbiology, 144 (1), 241-248.

Mahadevaswamy, M.; Mall, I. D.; Prasad, B.; Mishra, I. M. (1997). Removal of phenol by adsorption on coal fly ash and activated carbon, Pollut. Res., 16 (3), 170 - 175.

Monod, J. (1949). The growth of bacterial cultures., Ann. Rev. Microbiol., 3, 371-394.

Nikakhtari, H.; Hill, G. A. (2006). Continuous bioremediation of phenol-polluted air in an external loop airlift bioreactor with a packed bed., J. Chem. Technol. Biotechnol., 81(6), 1029-1038.

Oboirien, B. O.; Amigun, B.; Ojumu, T. V.; Ogunkunle, O. A.; Adetunji, O. A.; Betiku, E.; Solomon, B. O., (2005). Substrate inhibition kinetics of phenol degradation by Pseudomonas aeruginosa and Pseudomonas fluorescence., Biotechnol., 4(1), 56-61.

Paller, G.; Hommel, R. K.; Kleber, H. P., (1995). Phenol degradation by Acinetobacter calcoaceticus NCIB 8250., J. Basic Microbiol., 35 (5), 325 - 335.

Pirt, S. J., (1975). Principles of microbe and cell cultivation. Blackwell scientific publication, Oxford, United Kingdom.

Prpich, G. P.; Daugulis, A. J., (2005). Enhanced biodegradation of phenol by a microbial consortium in a solid-liquid twophase partitioning bioreactor., Biodegradat., 16 (4), 329-339.

Reardon, K. F.; Mosteller, D. C.; Rogers, J. D. (2000). Biodegradation kinetics of benzene, toluene and phenol and mixed substrates for Pseudomonas putida F1., Biotechnol. Bioeng., 69 (4), 385-400.

Ruiz-ordaz, N.; Ruiz-Lagunez, J. C.; Castanou-Gonzalez, J. H.; Hernandez-Manzano, E.; Cristiani-Urbina, E.; GalindezMayer, J., (1998). Growth kinetic model that describes the inhibitory and lytic effects of phenol on Candida tropicalis yeast, Biotechnol. Prog., 14 (6), 966-969.

Ruiz-ordaz, N.; Ruiz-Lagunez, J. C.; Castanou-Gonzalez, J. H.; Hernandez-Manzano, E.; Cristiani-Urbina, E.; GalindezMayer, J. (2001). Phenol biodegradation using a repeated batch culture of Candida tropicalis in a multistage bubble column, Revista Latinoamericana de Microbiogia, 43, 1925.

Saez, P. B.; Rittman, B. E. (1991). Biodegradation kinetics of 4 - chlorophenol, an inhibitory co-metabolite., Res. J. Water pollut. Control Fed., 63 (6), 838-847.

Saravanan, P.; Pakshirajan, K.; Saha, P. (2008). Growth kinetics of an indigenous mixed microbial consortium during phenol degradation in a batch reactor, Bioresource. Tech., 99 (1), 205-209.

Schroeder, M.; Muller, C.; Posten, C.; Deckwer, W-D.; Hecht, V. (1997). Inhibition kinetics of phenol degradation from unstable steady state data., Biotechnol. Bioeng., 54 (6), 567-576. 
Sokol, W. (1988). Dynamics of continuous stirred-tank biochemical reactor utilizing inhibitory substrate., Biotechnol. Bioeng., 31 (3), 198-202.

Solomon, B. O.; Posten, C.; Harder, M. P. F.; Hecht, V.; Deckwer, W-D. (1994). Energetics of Pseudomonas cepacia growth in a chemostat with phenol limitation, J. Chem. Tech. Biotechnol., 60 (3), 275-282.

Yang, R. D.; Humphrey, A. E. (1975). Dynamic and steady state studies of phenol biodegradation in pure and mixed cultures, Biotechnol. Bioeng., 17 (8), 1211-1235.
Yano, T.; Koga, S. (1969). Dynamic behaviour of the chemostat subject to substrate inhibition, Biotechnol. Bioeng., 11 (2), 139 - 153.

Zilli, M.; Converti, A.; Lodi, A.; DelBorghi, M.; Ferraiolo, G. (1993). Phenol removal from waste gases with a biological fitter by Pseudomonas putida, Biotechnol. Bioeng., 41, $693-699$.

\section{AUTHOR (S) BIOSKETCHES}

Agarry, S. E., Biochemical Engineering Research Laboratory, Department of Chemical Engineering, Ladoke Akintola University of Technology, Ogbomoso, Nigeria. Email: sam_enagarry@yahoo.uk.co

Solomon, B. O., Biochemical Engineering Research Laboratory, Department of Chemical Engineering, Obafemi Awolowo University, Ile-ife, Nigeria. Email: bosconsult@yahoo.com

This article should be referenced as follows:

Agarry, S. E.; Solomon, B. O., (2008). Kinetics of batch microbial degradation of phenols by indigenous Pseudomonas fluorescence. Int. J. Environ. Sci. Tech., 5(2), 223-232. 